\title{
Syngas Formation by Microwave-induced Platinum/Palladium/Rhodium Spent Catalyst
}

\author{
Chin Chung Lo, ${ }^{1}$ Chien Li Lee, ${ }^{2}$ Tsung-Yueh Tsai, ${ }^{1}$ and Chih-Ju G. Jou ${ }^{1 *}$ \\ ${ }^{1}$ Department of Safety, Health and Environmental Engineering,
National Kaohsiung University of Science and Technology, 2 Juoyue Road, Nantz District, Kaohsiung 811, Taiwan
${ }^{2}$ Research and Development Center for Water Resource and Conservation,
National Kaohsiung University of Science and Technology, 2 Juoyue Road, Nantz District, Kaohsiung 811, Taiwan
}

(Received August 1, 2019; accepted December 18, 2019)

Keywords: microwave, syngas, spent catalyst, micron iron

A platinum/palladium/rhodium $(\mathrm{Pt} / \mathrm{Pd} / \mathrm{Rh})$ spent catalyst $(\mathrm{Pt} / \mathrm{Pd} / \mathrm{Rh}$ ratio of about $0.16 / 0.001 / 0.01 \mathrm{wt} \%$ ) supported on $\mathrm{MgO}-\mathrm{Al}_{2} \mathrm{O}_{3}-\mathrm{SiO}_{2}$ as the main carrier was studied in the methane partial oxidation process. By utilizing the characteristics of microwave selectivity to couple with the material with high dielectric losses, micron iron powder was chosen during the microwave treatment since it has a higher dielectric constant than the $\mathrm{Pt} / \mathrm{Pd} / \mathrm{Rh}$ components. It was placed at the bottom of the reactor, where it could absorb microwave energy and convert it into heat energy, thereby enabling the partial oxidation reaction to occur. Under the same experimental conditions, namely, $\mathrm{CH}_{4} /$ air volume ratio of 1:2, microwave power of $450 \mathrm{~W}$, and reaction time of $330 \mathrm{~min}$, the results showed that the yields of syngas were higher when the micron iron was used with the $\mathrm{Pt} / \mathrm{Pd} / \mathrm{Rh}$ spent catalyst than when the catalyst was used alone. The yields were 67.3 and $11.6 \%$, compared with 41.5 and $11.5 \%$, for $\mathrm{H}_{2}$ and $\mathrm{CO}$, respectively, when using the micron iron combined catalyst rather than micron iron alone. It was also found that the coke deposed on the surface of the $\mathrm{Pt} / \mathrm{Pd} / \mathrm{Rh}$ catalyst had a filamentous shape.

\section{Introduction}

Syngas, which is mainly a mixture of carbon monoxide $(\mathrm{CO})$ and hydrogen $\left(\mathrm{H}_{2}\right)$, is an important raw material for the chemical industry. It can be used to produce liquid fuels and chemicals with high commercial value. It is often used as feedstock in the Fischer-Tropsch process, as well as to make ammonia and methanol in the petrochemical industry. ${ }^{(1)}$

Methane is the preferred raw material for syngas production because the cost of the final product is relatively low. ${ }^{(2)}$ There are generally four methods of producing syngas from methane: steam reforming, autothermal reforming, dry reforming, and catalytic partial oxidation. $^{(3,4)}$ Partial oxidation to syngas has gradually become a promising alternative to steam recombination, ${ }^{(5,6)}$ mainly because of three advantages: (1) Partial oxidation is a mild exothermic reaction, which could save energy in industrial applications. ${ }^{(6,7)}$ (2) The molar ratio of $\mathrm{H}_{2}$ to $\mathrm{CO}$ is close to 2 , which is an ideal feedstock ratio for subsequent processing *Corresponding author: e-mail: george@nkust.edu.tw https://doi.org/10.18494/SAM.2020.2579 
units such as methanol synthesis and the Fischer-Tropsch process. (3) The residence time is only a few milliseconds for the partial oxidation, which is much shorter than that of steam recombination (residence time usually in the range of $0.5-1 \mathrm{~s}$ ); the lower cost of investment and smaller production scale could achieve the required amount of syngas production in terms of development.

Precious metal catalysts are widely used for partial oxidation reactions. Although they are more expensive than other types of catalyst, precious metal catalysts exhibit high activity and good characteristics in partial oxidation reactions (such as a relatively low carbon deposition rate). Under the same conditions, the order of conversion activity is $\mathrm{Ph} \sim \mathrm{Ru}>\mathrm{Ir}>\mathrm{Pt}>\mathrm{Pd}$ catalysts. ${ }^{\left({ }^{(8)}\right.}$ $\mathrm{Rh}$ and $\mathrm{Ru}$ catalysts have high activity and produce hardly any carbon deposits (coke). Ni catalysts are cheaper than $\mathrm{Rh}$ and $\mathrm{Ru}$, but they deposit coke faster, leading to the rapid loss of activity of the catalyst. ${ }^{(9)}$ Bitsch-Larsen et al. studied the partial oxidation of catalysts with noble metal catalysts. ${ }^{(10)}$ The results showed that these catalysts are highly active, selectively convert methane into syngas with millisecond contact time, and form a small amount of coke. ${ }^{(10)}$ Furthermore, Bhagiyalakshmi et al. (2010) studied the effects of catalysts, such as Pt single, $\mathrm{Pt} / \mathrm{Rh}$ bimetallic, and $\mathrm{Pt} / \mathrm{Pd} / \mathrm{Rh}$ ternary catalysts, in low-temperature catalyzed methane combustion reactions $\left(150-600{ }^{\circ} \mathrm{C}\right) .{ }^{(11)}$ Their results showed that to reach the same conversion rate, the $\mathrm{Pt} / \mathrm{Pd} / \mathrm{Rh}$ ternary catalyst requires the lowest temperature, followed by bimetallic $\mathrm{Pt} / \mathrm{Rh}$, while the single metal Pt catalyst needs the highest temperature. ${ }^{(11)}$

The traditional heat treatment is usually indirect heating. Energy transfer is through convection, conduction, and radiation heat on the surface of the material, and through a thermal gradient. ${ }^{(12-14)}$ Microwave energy transfer is the direct transmission of heat generated by the interaction between molecules and an electromagnetic field. The electromagnetic energy generated is converted into heat energy. The heating is fast and uniform, which is considered to be volume heating. ${ }^{(15-17)}$ Microwave energy is directly converted into heat inside the material. The advantages of microwave heating include uniform and fast heating, energy saving, and a short reaction time to synthesize chemicals, as well as selective and noncontact heating. ${ }^{(13-16)}$ Microwave heat treatment technology has been successfully applied in different fields, such as removing volatile pollutants, ${ }^{(18)}$ oil-water separation, ${ }^{(19)}$ and treatment of halogen organic pollutants with the assistance of catalysts (nanoscale zero-valent copper, iron, and titanium dioxide). ${ }^{(20-22)}$

In this study, a $\mathrm{Pt} / \mathrm{Pd} / \mathrm{Rh}$ spent catalyst combined with micron iron powder was used to produce syngas by the partial oxidation of methane. The micron iron powder with a high dielectric constant was used to absorb microwave energy to convert it into heat energy, which was used as the heat source for syngas production and help increase the yield of production.

\section{Experimental Equipment and Method}

\subsection{Experimental equipment}

A microwave oven with $2.45 \mathrm{GHz}$ frequency was installed with proportional-integralderivative (PID) control of the output power, which has a maximum of $750 \mathrm{~W}$. An $80 \mathrm{~mL}$ quartz 
glass reactor equipped with 40 small holes distributed evenly at the bottom was used. The $\mathrm{Pt} / \mathrm{Pd} / \mathrm{Rh}$ spent catalyst (approximately 0.16:0.001:0.01 wt\%) was obtained from an abandoned automobile catalytic converter, which was supported on cordierite consisting of $\mathrm{MgO}-\mathrm{Al}_{2} \mathrm{O}_{3}-$ $\mathrm{SiO}_{2}$ compounds, and had a $0.4 \mathrm{wt} \%$ coke content.

\subsection{Experimental methods}

One layer of ceramic fiber insulation of about $2 \mathrm{~mm}$ thickness was placed on the bottom of the reactor. Then, $1 \mathrm{~g}$ of micron iron powder (particle size, $<212 \mu \mathrm{m}$ ) was spread evenly on the top of the ceramic fiber insulation. Another layer of insulation wool was laid on the top of the micron iron powder. Twelve grams of $\mathrm{Pt} / \mathrm{Pd} / \mathrm{Rh}$ spent catalyst was placed in the reactor, then it was placed in a microwave oven. The microwave power was maintained at $450 \mathrm{~W}$. The experimental variables were as follows: (1) for a continuous microwave time of $330 \mathrm{~min}$, mixed air and methane gas were introduced from the bottom of the reactor, and (2) the $\mathrm{CH}_{4} /$ air volume flow rate was changed from $10 / 10$ to $10 / 20(\mathrm{~mL} / \mathrm{min})$. The experimental equipment is shown in Fig. 1.

\subsection{Analyses}

Organic intermediates and final products were chemically analyzed using a gas chromatography-thermal conductivity detector (GC-TCD, SHIMADZU GC-2014). A tail gas sample $(1 \mu \mathrm{L})$ was taken every 30 min with three replicates for the measurements of $\mathrm{CO}$, $\mathrm{CO}_{2}, \mathrm{H}_{2}$, and $\mathrm{CH}_{4}$. In addition, the oxygen content was calculated on the basis of mass balance using the composition results obtained by GC analysis. The carrying gas (Ar) flow rate was maintained at $25 \mathrm{~mL} / \mathrm{min}$. The oven temperature was programmed to increase from 40 to $210{ }^{\circ} \mathrm{C}$ (at which it was held for $5 \mathrm{~min}$ ) at a ramp rate of $40^{\circ} \mathrm{C} / \mathrm{min}$, and the $\mathrm{GC}$ injector temperature was $120^{\circ} \mathrm{C}$.

Carbon Determinator (Eltra, CS 800) was used to analyze the coke content of the catalyst. Images produced by a scanning electron microscope (SEM) (Hitachi, SU8000) were used to observed the surface structure of the catalyst.

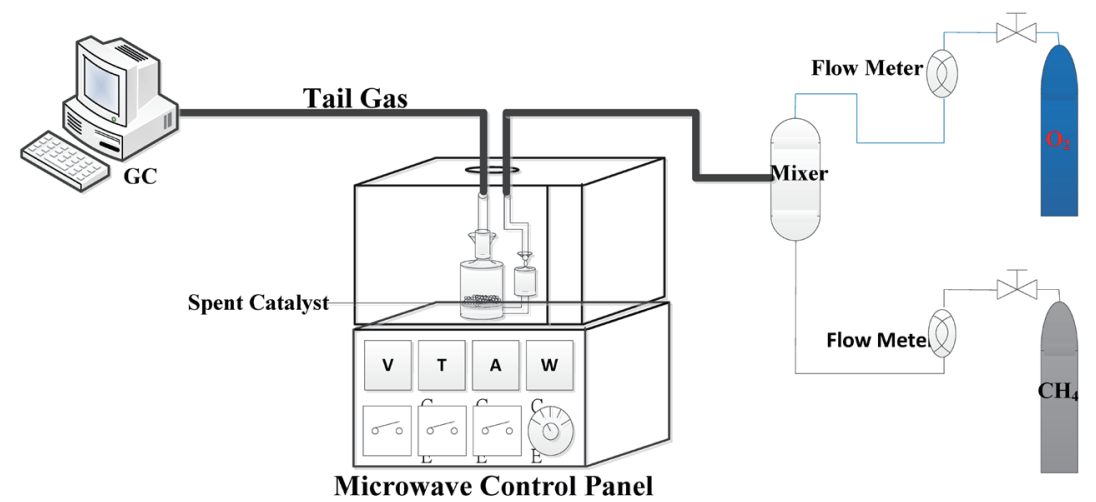

Fig. 1. (Color online) Experimental equipment. 


\section{Results and Discussion}

\subsection{Micron iron under microwave}

Micron iron is a high-dielectric-constant material $(14.2 \mathrm{~F} / \mathrm{m})$ that can effectively absorb microwave energy and convert it to heat energy, and its heating rate is $109^{\circ} \mathrm{C} / \mathrm{min}$. This heat energy can be used as a heat source for synthesis. The experiment conditions were set at the microwave power of $450 \mathrm{~W}$, an exposure time of $330 \mathrm{~min}$, and a volume flow ratio of $\mathrm{CH}_{4} / \mathrm{air}$ controlled at approximately $1: 1(10 / 10 \mathrm{~mL} / \mathrm{min})$ or $1: 2(10 / 20 \mathrm{~mL} / \mathrm{min})$.

As shown in Fig. 2, the average yields of $\mathrm{H}_{2}$ and $\mathrm{CO}$ are 13.1 and $12.4 \%$, respectively, when the $\mathrm{CH}_{4}$ /air ratio was 1:1. Significant condensation was formed at the reactor outlet in the first $60 \mathrm{~min}$. According to the partial oxidation mechanism, methane first oxidizes with oxygen to form $\mathrm{CO}_{2}$ and $\mathrm{H}_{2} \mathrm{O}$. Under the microwave conditions, when the volume flow ratio of $\mathrm{CH}_{4}$ /air was increased to $1: 2$, the average yields of $\mathrm{H}_{2}$ and $\mathrm{CO}$ were reduced to 11.6 and $11.5 \%$, respectively. In the latter part of the methane partial oxidation process, the remaining methane can be regenerated and reacted with hydrogen oxide to form $\mathrm{CO}$ and $\mathrm{H}_{2}$ by steam reforming and dry reforming with $\mathrm{CO}_{2}$.

\section{2 $\mathbf{P t} / \mathbf{P d} / \mathbf{R h}$ spent catalyst under microwave with micron iron}

As mentioned previously, micron iron can absorb microwave energy and convert it to heat energy as a heat source for the partial oxidation reaction. When utilizing the $\mathrm{Pt} / \mathrm{Pd} / \mathrm{Rh}$ spent catalyst in the process, the rate of the reaction increased significantly. Under the same microwave conditions, namely, a microwave power of $450 \mathrm{~W}$, a treatment time of $330 \mathrm{~min}$, and a $\mathrm{CH}_{4} /$ air ratio of 1:1 (10/10 mL/min), the results are as shown in Fig. 3 were obtained. The yields of $\mathrm{H}_{2}$ and $\mathrm{CO}$ reached 40.7 and $20.7 \%$, respectively. When the $\mathrm{CH}_{4}$ /air ratio was increased to $1: 2$, the yields of $\mathrm{H}_{2}$ and $\mathrm{CO}$ increased to 67.3 and $41.5 \%$, respectively. The coke content increased from 0.4 to 1.4 and $0.6 \%$, respectively, when the $\mathrm{CH}_{4} /$ air ratio was increased from 1:1 to 1:2.

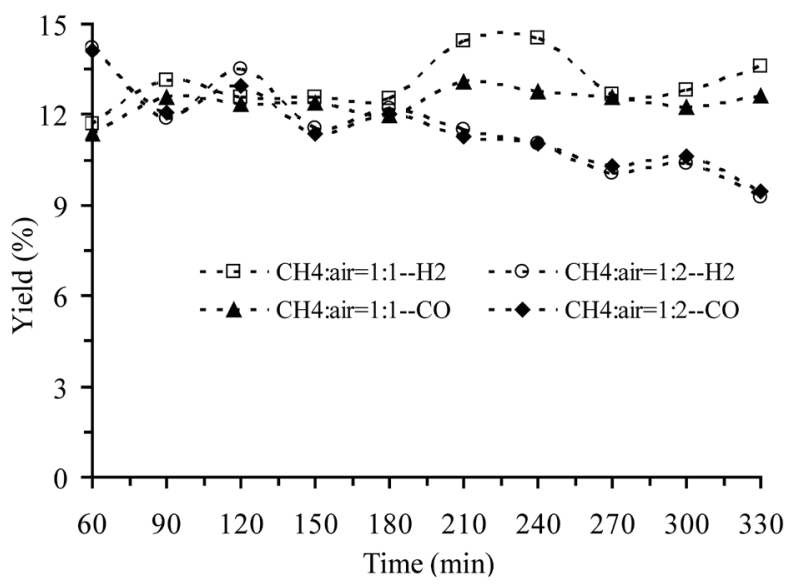

Fig. 2. Yields of $\mathrm{H}_{2} / \mathrm{CO}$ under microwave with micron iron.

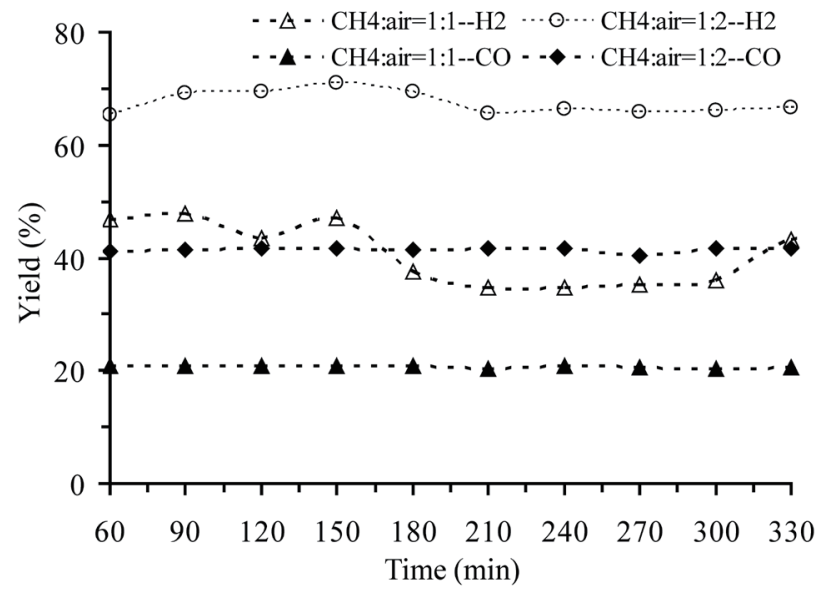

Fig. 3. Yields of $\mathrm{H}_{2} / \mathrm{CO}$ under microwave with micron iron and spent catalyst. 
The reaction temperature for methane partial oxidation is usually $1300-1400{ }^{\circ} \mathrm{C}$ to achieve a high conversion rate. However, it can be achieved at a low temperature and a short reaction time when a catalyst is used. ${ }^{(23,24)}$

Under the same microwave conditions and a $\mathrm{CH}_{4} /$ air ratio of $1: 2$, when $\mathrm{Pt} / \mathrm{Pd} / \mathrm{Rh}$ spent catalyst was used, the mean yield of $\mathrm{H}_{2}$ increased 5.8 times $(67.3$ vs $11.6 \%)$ and the mean yield of $\mathrm{CO}$ increased 3.6 times ( $41.5 \mathrm{vs} 11.5 \%$ ). This demonstrates that micron iron provides the heat source needed for the syngas production, while the $\mathrm{Pt} / \mathrm{Pd} / \mathrm{Rh}$ spent catalyst increases the rate of methane steam recombination and the dry recombination reaction, thereby increasing the $\mathrm{H}_{2}$ and $\mathrm{CO}$ yields.

\subsection{Structure analysis of catalyst}

The $\mathrm{Pt} / \mathrm{Pd} / \mathrm{Rh}$ spent catalyst carrier was cordierite in this study, which is composed of $\mathrm{MgO}-$ $\mathrm{Al}_{2} \mathrm{O}_{3}-\mathrm{SiO}_{2}$ compounds. The contents of elements $\mathrm{Mg}, \mathrm{Al}, \mathrm{Si}, \mathrm{Pt}, \mathrm{Pd}$, and $\mathrm{Rh}$ were determined by energy-dispersive X-ray spectroscopy (EDS) self-evident, as shown in Fig. 4.

The catalyst activity is higher when the influent volumetric $\mathrm{CH}_{4} /$ air ratio is $1: 1$ under a microwave power of $450 \mathrm{~W}$ and a treatment time of $330 \mathrm{~min}$, while the coke content of the catalyst increases from 0.4 to $1.4 \%$. Figure 5(b) shows an image of the catalyst after microwave treatment. The coke deposited on the surface of the catalyst had a filamentous shape, which is consistent with the findings of Suelves et al. ${ }^{(25)}$

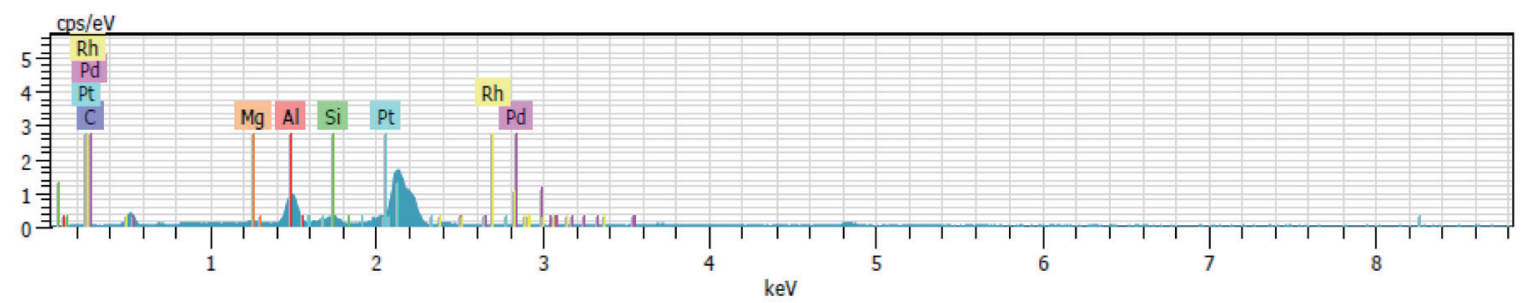

Fig. 4. (Color online) EDS spectra of spent $\mathrm{Pt} / \mathrm{Pd} / \mathrm{Rh}$ catalyst.

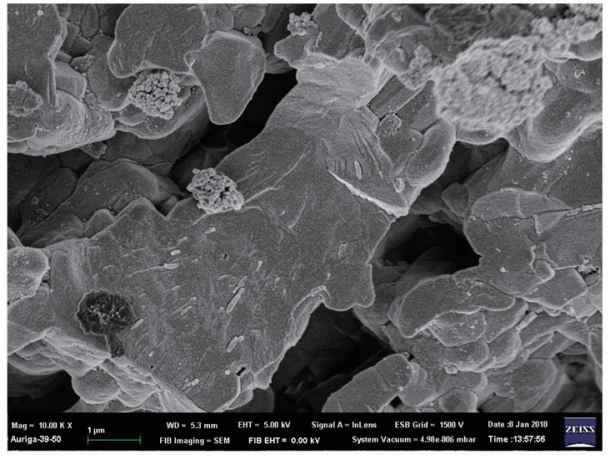

(a)

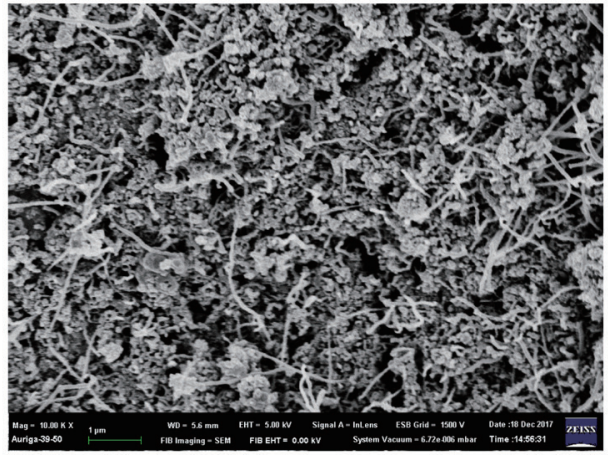

(b)

Fig. 5. Images of spent $\mathrm{Pt} / \mathrm{Pd} / \mathrm{Rh}$ catalyst: (a) before microwave treatment and (b) after microwave treatment. 


\section{Conclusions}

In this study, micron iron and a $\mathrm{Pt} / \mathrm{Pd} / \mathrm{Rh}$ spent catalyst were used to increase the reaction rate of methane partial oxidation to produce syngas under microwave treatment. Under the microwave conditions $\left(\mathrm{CH}_{4} /\right.$ air volume ratio, 1:2; microwave power, $450 \mathrm{~W}$; reaction time, $330 \mathrm{~min}$ ), the average yields of $\mathrm{H}_{2}$ and $\mathrm{CO}$ increased 5.8 times $(67.3$ vs $11.6 \%)$ and 3.6 times (41.5 vs $11.5 \%$ ), respectively, when using the $\mathrm{Pt} / \mathrm{Pd} / \mathrm{Rh}$ spent catalyst. Furthermore, the $\mathrm{Pt} / \mathrm{Pd} / \mathrm{Rh}$ catalyst has high activity and can easily cause coke deposition. After the reaction, the coke content of the $\mathrm{Pt} / \mathrm{Pd} / \mathrm{Rh}$ spent catalyst increased from 0.4 to $1.4 \mathrm{wt} \%\left(\mathrm{CH}_{4} /\right.$ air volume ratio, 1:1), and the coke deposited on the surface of the spent catalyst had a filamentous shape. In this study, we demonstrated an innovative technology to increase the yield of syngas production by microwave induction with the $\mathrm{Pt} / \mathrm{Pd} / \mathrm{Rh}$ spent catalyst combined with micron iron.

\section{References}

1 A. Donazzi, D. Livio, C. Diehm, A. Beretta, G. Groppi, and P. Forzatti: Appl. Catal. A 469 (2014) 52. https:// doi.org/10.1016/j.apcata.2013.09.054

2 M. Peymani, S. M. Alavi, and M. Rezaei: Appl. Catal. A 529 (2017) 1. https://doi.org/10.1016/j.apcata.2016.10.012

3 M. Peymani, S. M. Alavi, and M. Rezaei: Int. J. Hydrogen Energy 41 (2016) 6316. https://doi.org/10.1016/ j.ijhydene.2016.03.033

4 A. G. Dedov, A. S. Loktev, D. A. Komissarenko, K. V. Parkhomenko, A. C. Roger, O. A. Shlyakhtin, G. N. Mazo, and I. I. Moiseev: Fuel Process. Technol. 148 (2016) 128. https://doi.org/10.1016/j.fuproc.2016.02.018

5 Y. Ji, W. Li, H. Xu, and Y. Chen: Appl. Catal. A 213 (2001) 25. https://doi.org/10.1016/S0926-860X(00)00887-5

6 J. H. Jun, T. H. Lim, S. W. Nam, S. A. Hong, and K. J. Yoon: Appl. Catal. A 312 (2006) 27. https://doi. org/10.1016/j.apcata.2006.06.020

7 H. E. Figen and S. Z. Baykara: Int. J. Hydrogen Energy 40 (2015) 7439. https://doi.org/10.1016/ j.ijhydene.2015.02.109

8 M. Das and W. J. Koros: J. Membrane Sci. 365 (2010) 399. https://doi.org/10.1016/j.memsci.2010.09.029

9 S. Cimino, L. Lisi, and G. Mancino: Int. J. Hydrogen Energy 42 (2017) 23587. https://doi.org/10.1016/ j.ijhydene.2017.04.264

10 A. Bitsch-Larsen, R. Horn, and L. D. Schmidt: Appl. Catal. A 348 (2008) 165. https://doi.org/10.1016/ j.apcata.2008.06.036

11 M. Bhagiyalakshmi, R. Anuradha, S. D. Park, T. S. Park, W. S. Cha, and H. T. Jang: Bull. Korean Chem. Soc. 31 (2010) 120. doi:10.5012/bkcs.2010.31.01.120

12 M. S. Venkatesh and G. S. V. Raghavan: Biosyst. Eng. 88 (2004) 1. https://doi.org/10.1016/ j.biosystemseng.2004.01.007

13 W. Klinbun and P. Rattanadecho: Appl. Math. Modell. 36 (2012) 813. https://doi.org/10.1016/j.apm.2011.07.003

14 S. S. Lam and H. A. Chase: Energies 5 (2012) 4209. doi. 10.3390/en5104209

15 M. Bhattacharya and T. Basak: Energy 97 (2016) 306. https://doi.org/10.1016/j.energy.2015.11.034

16 J. A. Menéndez, A. Arenillas, B. Fidalgo, Y. Fernández, L. Zubizarreta, E. G. Calvo, and J. M. Bermúdez: Fuel Process. Technol. 91 (2010) 1. https://doi.org/10.1016/j.fuproc.2009.08.021

17 J. P. Robinson, C. E. Snape, S. W. Kingman, and H. Shang: J. Anal. Appl. Pyrolysis. 81 (2008) 27. https://doi. org/10.1016/j.jaap.2007.07.004

18 G. Xiong, X. He, and Z. Zhang: Anal. Chim. Acta 413 (2000) 49. https://doi.org/10.1016/S0003-2670(00)007546

19 S. Akbari, A. H. Nour, F. Fayaz, M. S. Halimi, and A. Nazari: Aust. Basic Appl. Sci. 10 (2016) 1. https://www. researchgate.net/publication/324841241

20 C. J. G. Jou, C. L. Lee, C. R. Wu, S. C. Hsieh, and P. K. Andy Hong: Environ. Chem. Lett. 9 (2011) 355. doi: 10.1007/s10311-010-0286-y

21 C. L. Lee, C. Lin, and C. J. G. Jou: J. Air Waste Manage. 6 (2012) 1443. doi: 10.1080/10962247.2012.719579

22 C. L. Lee and C. J. G. Jou: Environ. Pollut. 1 (2012) 159. doi:10.5539/ep.v1n2p159 
23 P. Aghalayam, Y. K. Park, N. Fernandes, V. Papavassiliou, A. B. Mhadeshwar, and D. G. Vlachos: J. Catal. 213 (2003) 23. https://doi.org/10.1016/S0021-9517(02)00045-3

24 G. Veser, J. Frauhammer, and U. Friedle: Catal. Today 61 (2000) 55. https://doi.org/10.1016/S09205861(00)00378-3

25 I. Suelves, M. J. Lázaro, R. Moliner, B. M. Corbella, and J. M. Palacios: Int. J. Hydrogen Energy 30 (2005) 1555. https://doi.org/10.1016/j.ijhydene.2004.10.006 